\title{
вмJ Global Health Is the current surge in political and financial attention to One Health solidifying or splintering the movement?
}

\author{
Julia Spencer, ${ }^{1,2}$ Ellen McRobie,,${ }^{1,3}$ Osman Dar, ${ }^{1}$ Afifah Rahman-Shepherd, ${ }^{1}$ \\ Nadeem Hasan, ${ }^{1}$ Johanna Hanefeld, ${ }^{4}$ Mishal Khan ${ }^{5}$
}

To cite: Spencer J, McRobie E, Dar 0 , et al. Is the current surge in political and financial attention to One Health solidifying or splintering the movement?BMJ Glob Health 2019;4:e001102. doi:10.1136/ bmjgh-2018-001102

Handling editor Peter MacGarr Rabinowitz

JS and EM are joint first authors.

Received 9 August 2018

Revised 20 December 2018

Accepted 21 December 2018

\section{Check for updates}

(C) Author(s) (or their employer(s)) 2019. Re-use permitted under CC BY-NC. No commercial re-use. See rights and permissions. Published by BMJ.

${ }^{1}$ Centre on Global Health Security, Chatham House, London, UK

${ }^{2}$ London School of Hygiene \& Tropical Medicine, London, UK ${ }^{3}$ Department of Infectious Disease Epidemiology, Imperial College London, London, UK ${ }^{4}$ Department of Global Health and Development, London School of Hygiene \& Tropical Medicine, London, UK ${ }^{5}$ Faculty of Public Health and Policy, London School of Hygiene \& Tropical Medicine, London, UK

Correspondence to Dr Mishal Khan; mishal.khan@lshtm.ac.uk

\section{ABSTRACT}

Introduction The global health field has witnessed the rise, short-term persistence and fall of several movements. One Health, which addresses links between human, animal and environmental health, is currently experiencing a surge in political and financial attention, but there are welldocumented barriers to collaboration between stakeholders from different sectors. We examined how stakeholder dynamics and approaches to operationalising One Health have evolved further to recent political and financial support for One Health

Methods We conducted a mixed methods study, first by qualitatively investigating views of 25 major policymakers and funders of One Health programmes about factors supporting or impeding systemic changes to strengthen the One Health movement. We then triangulated these findings with a quantitative analysis of the current operations of 100 global One Health Networks.

Results We found that recent attention to One Health at high-level political fora has increased power struggles between dominant human and animal health stakeholders, in a context where investment in collaboration building skills is lacking. The injection of funding to support One Health initiatives has been accompanied by a rise in organisations conducting diverse activities under the One Health umbrella, with stakeholders shifting operationalisation in directions most aligned with their own interests, thereby splintering and weakening the movement. While international attention to antimicrobial resistance was identified as a unique opportunity to strengthen the One Health movement, there is a risk that this will further drive a siloed, disease-specific approach and that structural changes required for wider collaboration will be neglected.

Conclusion Our analysis indicated several opportunities to capitalise on the current growth in One Health initiatives and funding. In particular, evidence from better monitoring and evaluation of ongoing activities could support the case for future funding and allow development of more precise guidelines on best practices.

\section{INTRODUCTION}

The inextricable connections between human health, animal health and the state of

\section{Key questions}

What is already known?

- The One Health movement is currently experiencing a rise in political and financial attention.

- There are well-documented barriers to collaboration between human, animal and environmental health specialists.

What are the new findings?

- Recent attention to One Health has increased power struggles and coordination challenges.

- Stakeholders are shifting operationalisation in directions most aligned with their own interests, thereby splintering the movement.

What do the new findings imply?

- The increase in organisations conducting diverse activities under the One Heath umbrella presents an opportunity to strengthen the evidence base to provide clearer guidance on priority areas.

the environment are in the spotlight vis-à-vis global health policymakers. ${ }^{1-4}$ For example, it has been estimated that $75 \%$ of all emerging diseases affecting humans originate from an animal source, causing 2.7 million deaths annually. ${ }^{5}$ Even more premature mortality, in excess of three million annual deaths, is attributed to outdoor air pollution, which is substantially driven by intensive livestock and crop production. ${ }^{67}$ Although the concept of integrating efforts to address health challenges that emerge at the human-animal-ecosystem interface is not new, ${ }^{8}$ a number of related movements have gained traction among health policymakers and funders over the past 15 years, including One Health, EcoHealth and Planetary Health. While these approaches are underpinned by differing values and assumptions, ${ }^{9}{ }^{10}$ they all broadly rally around a shared notion based on '...the collaborative effort of multiple 
disciplines—working locally, nationally and globally—to attain optimal health for people, animals, and our environment'. ${ }^{11}$

As this overarching aim suggests, the envisaged multidisciplinary approach relies on systemic changes to establish a more cross-cutting approach to research, surveillance and responses to global health challenges, breaking away from a disease-specific or siloed mode of operation. ${ }^{12-14}$ 'One Health', in particular, has received significant political attention and support, including being formally endorsed by a number of multilateral institutions, such as the World Health Organization (WHO), World Organization for Animal Health (OIE), Food and Agriculture Organization of the United Nations (FAO) and the World Bank. ${ }^{15-17}$ The One Health movement first gained this 'international currency' after the outbreak of highly pathogenic avian influenza (HPAI) in the early 2000s and the associated mobilisation of an international response jointly led by the FAO, OIE and WHO ${ }^{10}$ This response was widely regarded as an unprecedented paradigm shift in global governance as it marked a commitment for greater organisational collaboration and a departure from traditional siloed modes of working. ${ }^{18}$ Indeed, Chien argues that at the height of the avian influenza crisis, adopting an all-inclusive One Health approach served to reduce conflict between competing institutional priorities of FAO, OIE and WHO, defend legitimacy and facilitate a shared commitment for cooperation. ${ }^{18}$

Since 2010, political and financial attention to One Health has surged, with several developments in the last 3 years. The FAO, OIE and WHO launched a strategy for partnership (known as the Tripartite Concept Note) in April 2010 at the International Ministerial Conference on Animal and Pandemic Influenza in Vietnam (box 1). ${ }^{16}$ In recent years, collaboration based on One Health principles has been a topic of discussion

\section{Box 1 Summary of information about the Tripartite}

- In 2010, the FAO, OIE and WHO expressed their collective commitment to strengthening international collaboration and coordination of efforts in response to global health risks at the human-animal-ecosystem interface. This commitment was captured in a Tripartite Concept Note.

- In 2017, the Tripartite reaffirmed its commitment and leadership role in applying the principles of One Health to address global issues. Focus areas and scope of activities for the 2017 to 2020 period were defined as: antimicrobial resistance; food safety; early warning and surveillance/monitoring system; preparedness and response to emerging, re-emerging and neglected infectious diseases; and coordinated research and development.

- In May 2018, the Tripartite formalised their agreement in a Memorandum of Understanding, which provides a framework to further the FAO, OIE and WHO's '.... shared goals and objectives in regard to the development and implementation of multi-sectoral approaches'. ${ }^{17}$ It is reported that the Tripartite group is preparing a work plan and will be holding annual Tripartite Executive Coordination Meetings. at several high-level political fora, such as at the 2016 UN General Assembly, the 2015 G7 Health Ministers' Meeting and the 2016 Commonwealth Health Ministers Meeting. The Tripartite released a second strategic document in $2017,{ }^{19}$ reaffirming its commitment to 'more broadly embrace the One Health approach'. ${ }^{20}$ In parallel, there has been substantial investment in One Health and a rapid growth in the number of organisations stating that they are working to enhance collaboration across human, animal and environmental health sectors. $^{21-24}$

While this broader framing of One Health by the Tripartite and the recent surge in political and financial commitment has encouraged a wide range of organisations to join the One Health community, it has also meant that the One Health concept risks being appropriated by a range of different actors to label a range of different initiatives (table 1). ${ }^{10}$ Multiple interpretations of the concept have emerged, ${ }^{10}$ with actors often competing for attention and funding for their programmatic priorities. ${ }^{25}$ Galaz and colleagues identify three dominant narratives within the One Health community (the 'integration narrative', 'risk and surveillance narrative' and 'economic benefit narrative') that reflect very different institutional logics, power structures and agendas. ${ }^{10} 26$ These fractions and submovements within One Health are also reflected outside of the movement. For instance, Lerner and Berg argue that despite their similarities, important distinctions exist between EcoHealth, Planetary Health and One Health and that thus far these movements have struggled to work together despite calls ${ }^{27} 28$ for their convergence to strengthen collective efforts and to avoid duplication. ${ }^{9}$

Indeed, concern has been raised that the current surge in political and financial support for One Health is primarily driven by recent zoonotic disease outbreaks and crises ${ }^{10}$ and that structural changes to support collaboration between the human, animal and environmental health sectors have therefore been limited in focus. ${ }^{26}{ }^{29}{ }^{30}$ For example, a study in Nigeria found that while crises like HPAI have been instrumental in catalysing intersectoral action, efforts often return to 'business as usual' approaches in the aftermath of outbreaks, particularly if interventions are funded by external actors and if governance frameworks are not amended to facilitate long-term change. ${ }^{25}$ As this example suggests, it therefore remains to be seen whether stated commitment to applying a One Health ethos will be sustained in the long-term or whether it will be set aside in favour of other approaches. ${ }^{130}$

Against this background of heightened political and financial interest in One Health and existing research that highlights differing perspectives on how to operationalise One Health, ${ }^{10} 253132$ our study seeks to identify new opportunities and to examine longstanding barriers to sustaining political attention and realising systemic change. 
Table 1 Examples of One Health Networks identified through a systematic review, ${ }^{22}$ and a summary of the networks' selfreported activities

\begin{tabular}{|c|c|}
\hline Network name & Key activities \\
\hline $\begin{array}{l}\text { Connecting Organisations } \\
\text { for Regional Disease } \\
\text { Surveillance (CORDS) }\end{array}$ & $\begin{array}{l}\text { CORDS is a non-governmental organisation comprised of six regional networks that operate } \\
\text { across South East Europe, Southern and East Africa, South East Asia, The Mekong Basin } \\
\text { and the Middle East. The collective action of these networks-detecting and responding to } \\
\text { outbreaks at the community level-enables the organisation to 'exchange information between } \\
\text { surveillance systems globally'. CORDS applies a One Health approach to their surveillance and } \\
\text { monitoring, data and information sharing and communication and collaboration activities, as } \\
\text { well as capacity building. }\end{array}$ \\
\hline $\begin{array}{l}\text { One Health Commission, } \\
\text { One Health Platform, One } \\
\text { Health Initiative }\end{array}$ & $\begin{array}{l}\text { These organisations work collaboratively to operationalise the One Health approach by } \\
\text { connecting One Health actors, creating strategic networks and partnerships, and raising } \\
\text { awareness of the approach and key One Health issues. The One Health Commission mainly } \\
\text { functions as a communication and collaboration platform, facilitating data and information } \\
\text { exchange as well as advocating and building capacity in One Health. }\end{array}$ \\
\hline $\begin{array}{l}\text { USAID Emerging Pandemic } \\
\text { Threats } 2 \text { (EPT 2) } \\
\text { Programme, Preparedness } \\
\text { and Response (P\&R) and } \\
\text { One Health Workforce } \\
\text { (OHW) Projects }\end{array}$ & $\begin{array}{l}\text { Under the umbrella of the USAID EPT } 2 \text { Programme, the P\&R Project is charged with } \\
\text { establishing and strengthening National One Health Platforms across Africa and South East } \\
\text { Asia. The Project focuses on activities pertaining to disease surveillance and monitoring, } \\
\text { national-level capacity building, communication and collaboration and is responsible for } \\
\text { disbursing funds to support One Health activities. } 667 \\
\text { Another branch of the EPT2 Programme, the OHW Project aims to transform the health } \\
\text { workforce through two established university networks-the One Health Central and Eastern } \\
\text { Africa (OHCEA) network and the South East Asia One Health University Network (SEAOHUN)- } \\
\text { and is mainly focused on capacity building activities. }{ }^{68}\end{array}$ \\
\hline
\end{tabular}

\section{METHODS}

We conducted a mixed methods study between June 2017 and June 2018, first qualitatively investigating views held by major policymakers and funders of One Health programmes about the factors impeding or supporting political attention and a shift from rhetoric (expressed commitment) to long-term systemic changes. We then triangulated these findings with quantitative data about the current strategic functioning-including scope of work, regions of focus and stakeholders engaged-of One Health Networks (OHNs).

\section{Qualitative study}

We focused our qualitative study on 'elite policymakers', which we defined as representatives from organisations that hold a degree of influence over the global One Health agenda owing to the organisations' control of funding or of leadership in the development of guidelines and policies for One Health. Two pilot interviews, followed by two rounds of interviews, were conducted with 25 informants. A first set of informants were selected purposively by identifying a list of key organisations involved in One Health activities. These included the Tripartite organisations-the FAO, OIE and WHO-and major One Health funders, such as USAID and the World Bank. This was followed by snowball sampling based on recommendations from informants. During the snowballing process, efforts were made to identify representatives across human, animal and environmental health disciplines and different sectors, such as academia and intergovernmental organisations, including dissenting voices. All elite policymakers identified were based in Europe or the USA.
We invited the most senior representative working on One Health issues from each organisation to participate in the interviews. Interview questions explored the relationship dynamics between the many actors working in the One Health policy space, the political context in which these actors operate, governance arrangements and views on the progress made towards operationalising One Health. Interviews were predominantly conducted by telephone or by Skype (two were conducted in person) in English and lasted between 30 and $75 \mathrm{~min}$. Key informant affiliation types are detailed in table 2. After seeking informed consent, interviews were audio recorded and transcribed verbatim. No informants declined recording or transcription of their interview and it was agreed that organisational characteristics could be included when reporting results, along with verbatim quotes, but individual's personal details would remain anonymous. Transcripts and research notes were managed and analysed in Dedoose.

The researchers followed guidance detailed by Fernald and Duclos on approaches for conducting qualitative analysis in teams. ${ }^{33}$ Following an initial round of inductive analysis, codes and definitions were discussed by the research team and an initial set of primary codes was agreed on. Further inductive and deductive rounds of coding were then completed. Our analysis was guided by frameworks developed by Shiffman and colleagues on the determinants of political priority ${ }^{34}$ and on the emergence and effectiveness of global health networks. ${ }^{35} \mathrm{We}$ focused on three components presented in these frameworks: actor power (the strength of the individuals and organisations operating in the One Health community), 
Table 2 Key informants interviewed are coded by affiliation type, followed by their informant number and the region in which they are based, for example, informant number two is coded as 'MG2EUR'

\begin{tabular}{|c|c|c|c|}
\hline \multirow[b]{2}{*}{ Affiliation type } & \multicolumn{2}{|l|}{ Region } & \multirow[b]{2}{*}{ Total } \\
\hline & Europe (EUR) & USA & \\
\hline Organisation with multigovernment membership (MG) & $2,7,13,15,18,19$ & 24 & 7 \\
\hline Single government organisation (G) & 4 & 8,9 & 3 \\
\hline Networking platform for One Health (N) & 1,3 & 6,14 & 4 \\
\hline University or One Health research body (U) & $5,11,20,21,25$ & $10,12,16,22$ & 9 \\
\hline Private funding body $(F)$ & 23 & & 1 \\
\hline For-profit company (FP) & & 17 & 1 \\
\hline Total & 15 & 10 & 25 \\
\hline
\end{tabular}

Source: Authors' tabulation of informants' data.

political context (the environment in which these actors operate) and issue characteristics (key features of the One Health approach).

\section{Quantitative analysis of One Health Networks (OHNs)}

We analysed quantitative data collected by the authors for a larger study on the strategic functioning of OHNs in order to triangulate findings from the qualitative analysis and to serve as a case study of actor networks operating in One Health. ${ }^{22}$ Briefly, Khan and colleagues defined an $\mathrm{OHN}$ as an engagement between two or more discrete organisations or government entities with at least two of the following sectors represented: animal health, human health and environment/ecosystem. Through a systematic search of numerous academic and grey literature sources, the group identified 100 OHNs and extracted information about their operations with respect to the networks' geographical focus, engagement across human, animal and environment health sectors, key activities, stakeholder involvement and accountability structures using a standardised extraction template. This information was used to analyse network characteristics and activities, specifically in relation to findings emerging from the qualitative study.

\section{Presentation and feedback on findings}

We validated our findings by sharing preliminary results of the quantitative and qualitative analyses with approximately 50 international participants at the Prince Mahidol Award Conference during a special session on One Health (Bangkok, January 2018).

\section{Ethical approval}

Ethical approval for the research was received from the London School of Hygiene \& Tropical Medicine ethics committee.

\section{RESULTS}

We first present the main findings from our qualitative analysis and, where relevant, show data from the case study of OHNs that could provide objective insights to triangulate views held by interviewees.

\section{Power struggles between stakeholder groups impede the establishment of required systemic changes}

From the perspective of all respondents, despite acceptance of the importance of a One Health approach by a wider group of policymakers and funders in recent years, One Health implementers have struggled to coalesce around an operational definition that will lead to tangible systemic changes to improve multisectoral collaboration:

'What do we want to achieve in ten years or twenty years with this One Health concept? Okay, we want that the sectors work together, better and so on, but what does it mean exactly? Working better, working together, what does it mean?' (MG15EUR).

A lack of clarity on how to achieve synergistic working across the animal, human and environmental health sectors was perceived to stem from, and lead to, conflict between different stakeholder groups in the movement, hampering their capacity to act collectively (U20EUR; U12US; MG19EUR; U10US; U21EUR; F23EUR). Power relations appeared to be at the root of this problem, with all respondents commenting on an inequitable distribution of power in terms of decision-making and funding between the three sectors. However, which sector yielded the most power was contested. Some respondents (U5EUR; U10US; U12US; U16US; N14US; U20EUR; U21EUR) commented on the historic dominance of the veterinary sector, but noted this sector's limited power compared with human health practitioners at present. One respondent summarised this sentiment: '....and [animal health stakeholders] don't even know there's a table to sit around because it's run from the human side, by the humans, and the vets are told what to do' (MG18EUR). All informants perceived human health practitioners to occupy a privileged position in the movement, which some perceived as an impediment to collaboration (N14US; MG7EUR; MG18EUR; U16US; U10US). One interviewee additionally indicated that the increase 
in political and financial attention to One Health is driving the human health sector to try and retain control:

'I think there's a fear of loss of control. Medical professionals tend to want to be...in charge of health. They don't want to share their authority, and I think that continues to be a challenge' (U10US).

It was felt that power differences between the human and animal health sectors may be rooted in a lack of respect for technical expertise of veterinary health actors among human health practitioners:

'I think there is a historical, yeah, I'll say it, lack of respect for the science coming out of the veterinary domain. They say, 'Oh, what do they do? They spend their time wondering about farms, they don't know anything about science,' and I think that's been a culture that we've had to battle...'

(MG18EUR).

Additionally, it was suggested that stakeholders trying to operationalise One Health lacked the essential skills and knowledge necessary for overcoming power struggles and introducing systemic changes to support interdisciplinary working (U12US; U25EUR), with concerns raised that members of the movement tend to have expertise in their respective fields but do not have a clear understanding of other members' approaches, which impedes effective collaboration:

'And the human health people really [need] to learn some basic veterinary things. And both of them need to learn some principles of environmental health. And we're not really pushing that...' (U12US).

Several respondents noted the need to develop and expand on existing training and educational initiatives for One Health (at the secondary and tertiary level) so that the next cohort of leaders are better equipped to overcome organisational silos (N6US; MG7EUR; N14US; U21EUR; MG24US).

Although all respondents stressed the need to involve a diverse group of stakeholders (in terms of discipline and sector) in the movement, they also raised concern that such diversity can impede cohesion and foster disagreement between stakeholders, as illustrated below:

\footnotetext{
'...People come with their own ideas of what One Health is and they have their own expectations and their own agendas and bringing everybody together in one network and then having a common voice, I think that's quite difficult' (U20EUR).
}

Another respondent (NGO20EUR) explained that there are challenges to bringing diverse voices together and that this may explain why some stakeholders are less frequently represented in One Health collaborations. Although interview respondents focused on the balance of power between human and animal health stakeholders, our quantitative analysis of stakeholders currently involved in OHNs revealed that it was actually the environmental health sector that was poorly represented in OHNs; $31 \%$ of OHNs analysed included human and animal health stakeholders without a representative from the environmental sector, whereas only $3 \%$ did not include an animal health stakeholder and $2 \%$ did not include a human health stakeholder. We also found that government bodies and academic institutions are represented in $78 \%$ and $76 \%$ of all networks, respectively. In contrast, private for-profit organisations were engaged in $23 \%$ of OHNs and members of communities affected by OHN activities in $10 \%$ of collaborations.

Diverse views of informants indicated that the role of the for-profit private sector was particularly contentious. The majority of respondents noted minimal engagement of the private sector; however, perspectives on the best way forward were divided. Five respondents viewed the for-profit private sector as under-represented in the One Health community (MG18EUR; G8US; G4EUR; FP17US; U10US), and as such, argued that they should be further engaged to leverage their unique expertise. In contrast, three respondents argued that private sector actors should not have a role in One Health due to the existence of an innate conflict between public and private interests (MG18EUR; MG15EUR; U25EUR). Another three respondents took a more nuanced approach and argued that the private sector should only be engaged sometimes and under certain circumstances (MG2EUR; N3EUR; U20EUR) to avoid them becoming unduly influential. For example, it was proposed that while private sector actors should generally be consulted, they should not be involved in decision-making when they have a financial stake in the issue under discussion, stating that they: '...would not invite people who have a commercial interest to the table' (MG2EUR).

Although our analysis of OHNs showed that $54 \%$ of collaborations involved a civil society or non-governmental stakeholder, one participant argued that sustained action on furthering One Health will be impeded in part due to minimal engagement with civil society organisations (U10US). They further argued that the movement predominantly engages select 'technocrats' and that increased involvement of civil society '... [can] ultimately drive One Health to be more widely engaged...' (U10US).

\section{Lack of agreement on leadership and governance structures is a core issue}

Respondents identified weak guiding institutions as a critical challenge to operationalising the One Health approach. It was generally agreed that, at present, the Tripartite Agreement of the FAO-OIE-WHO was the '.. centre of gravity...' (G8US) for the movement, and as such, was well placed to assume a leadership role at the global level; however, views on the effectiveness of this partnership varied. Some respondents depicted the Tripartite as a key enabler. For example, one informant commented on its capacity to set a model for country-level networks: 'The ability of the Tripartite to...come together, help identify clear strategic priorities, we see as a big enabler and that's what we encourage at the national level as well' (MG13EUR). In contrast, others voiced concerns 
regarding the Tripartite's capacity to effectively collaborate and lead. A respondent with significant experience working in partnership with the FAO, OIE and WHO, reflected on the challenges associated with bringing together the distinct organisational cultures, priorities, approaches and interests of the Tripartite's members: 'You'd have better luck with a shotgun marriage...there are such cultural divides between those three organisations...so they're having a hard time' (G8US).

Some respondents' perceptions also oscillated between the normative and political benefits of the Tripartite, and its practical contributions: 'They haven't done so much yet...I think they endorse the concept but I think in terms of practical implementation and change, not so much is happening' (U20EUR).

More than half of all respondents commented on the need to develop guidelines and core values or competencies shared across One Health stakeholders in order to operationalise One Health. However, a few respondents did not agree that standardisation and centralised coordination was the best way forward:

'I'm sure collectively the effort will do a lot of good and it's perhaps not entirely realistic to think that [One Health] should have a nice, tidy governance structure that we can all understand and that's coherent. I see it as inevitably messy' (MG13EUR).

It was further argued by one interviewee that centralised governance arrangements and the standardisation of approaches may in fact impede One Health operationalisation by stifling adaptability in the field, cautioning against '... One Health becoming a straightjacket' and playing '...the game of power around leadership and imposing things...because it's probably not what we need with One Health' (MG24US). Despite differences in views about One Health governance, there was broad agreement about the need for better coordination across OHNs.

\section{Attention to antimicrobial resistance (AMR) presents opportunities and challenges for advancing a broad One Health approach}

Respondents identified increased national-level and global-level attention to AMR as a critical opportunity for One Health approaches to be prioritised (N3EUR; U5EUR; U16US; MG18EUR; U22US; F23EUR). Concerns were expressed that One Health may not be able to maintain traction during 'peacetime' if the approach only gains attention during outbreaks: 'We're all dancing around Big Bang, and pandemics, and the next Ebola' (MG24US). Contrasting AMR to Ebola in terms of harnessing political attention, it was noted that AMR is a global phenomenon that will remain a salient concern in the long term:

\footnotetext{
'...the issue of emerging pandemic threats is certainly one that galvanises people around One Health... but not every country is subject to the threat of Ebola... On the other hand, just about everybody in the world today is suffering or going to suffer from the effects of AMR...If I were to
}

recommend where the future of One Health activities and resources ought to be applied, I would say it's in AMR' (FP17US).

Some respondents (U16US; MG18EUR) also noted that AMR provides an opportunity to overcome sectoral silos and to generate greater cohesion among concerned actors, which, as discussed earlier, has been challenging thus far.

Despite widespread acknowledgement of the opportunities AMR presents for further operationalisation of One Health, our quantitative analysis suggests that AMR was not a significant focus area for OHN activities as stated on websites or publicly available documents. While the majority $(67 \%)$ of OHNs focused on addressing communicable diseases, only five of these networks stated that they work on AMR. Overall, 32\% of networks did not work on any specific disease area and instead stated that their activities covered systems strengthening functions, such as capacity building or communication broadly.

\section{Absence of an evidence base to justify future investments in One Health may result in dwindling political and financial support}

Several informants (N3EUR; U12US; U20EUR; U21EUR; U22US) noted exceptional challenges in developing credible indicators to assess the impact of applying a One Health approach, which may result in limited evidence about the results of ongoing investments and activities. In line with this sentiment, the quantitative case study found that while $74 \%$ of OHNs clearly defined their mission, vision or objective, only half of all networks stated their projected outputs or goals, and only $15 \%$ referred to a monitoring and evaluation (M\&E) strategy on their website. This low reporting of specific M\&E plans or indicators of success may reflect the challenge described by interviewees of standardising One Health operations and impact assessment.

There were conflicting views on whether there should be standardised indicators to assess severity of diseases and impact of a One Health approach. The complexity of One Health interventions was discussed frequently (N6US; U12US; FP17US; MG18EUR; F23EUR) with one respondent noting: '... There are so many dimensions to it that it makes your head spin' (F23EUR). A named effort to improve standardisation of outcome reporting in order to improve the evidence base for One Health was the Checklist for One Health Epidemiological Reporting of Evidence (COHERE). ${ }^{12}$ One respondent advised learning from best practice in regions that were perceived to be more advanced in operationalizing One Health, such as East Asia, '...to avoid reinventing the wheel...' (MG18EUR). However, several respondents commented that One Health approaches are likely to be highly context specific (G8US; G9US; U16US; FP17US; U22US).

Four informants (N3EUR; N6US; MG15EUR; U22US) spoke of the absence of a robust evidence base to demonstrate the added value of applying a One Health 
approach, with concern expressed that difficulties in providing evidence of impact from investments in One Health may hamper sustainability:

'I think many networks have been created when One Health was trendy...but at the end they have not been very sustainable because what was missing is really what is the added value of this network' (MG15EUR).

\section{DISCUSSION}

Our investigation of evolutions in the One Health movement following a recent surge in political and financial attention identified new and longstanding challenges to enhanced collaboration. Attention to One Health at high-level political fora appears to have only increased power struggles around who 'owns' the One Health movement, particularly between dominant human and animal health stakeholders. A key point highlighted is that stakeholders driving the movement had not substantially developed their collaboration-building skills and often lacked the respect or awareness for disciplines other than their own. As indicated by our qualitative and quantitative data, the injection of funding to support One Health activities has been accompanied by a rise in organisations working in this area; however, we found that this has also lead to difficulties in coordination of various fractions, ${ }^{10}$ with notable gaps in representation of certain groups, such as civil society organisations. Finally, even though the Tripartite collaboration has made progress through the development of working agreements and guidelines, the majority of interviewees felt strongly that more was needed in terms of guidance on implementation and to facilitate coordination of activities. Our analysis suggests that the absence of clearer guidelines for organisations implementing One Health activities may be related to the weak evidence base to identify areas to prioritise for continued investment.

These findings build on a growing literature of One Health policy analysis, ${ }^{10} 18253132$ particularly on the issue of the lack of involvement of civil society organisations in the One Health movement and on power struggles within the community. ${ }^{10} 18$ As mentioned in the introduction, One Health gained its prominence following the increasing interaction between the FAO, OIE and WHO in response to the avian influenza outbreak in the early 2000s. ${ }^{18}$ In contrast to other global health initiatives, One Health was driven by these international organisations whereas the role of civil society organisations and affected communities has been largely neglected. ${ }^{10}$ At the centre of the AIDS movement, for example, were the communities affected by HIV and they were critical for generating attention and resources to sustain a long-term response, such as the establishment of the Global Fund to Fight AIDS, Tuberculosis and Malaria and bringing a health issue to the UN Security Council. ${ }^{36} 37$ As this example suggests, linking with civil society groups working on issues relevant to One Health is important for generating widespread political support for the movement rather

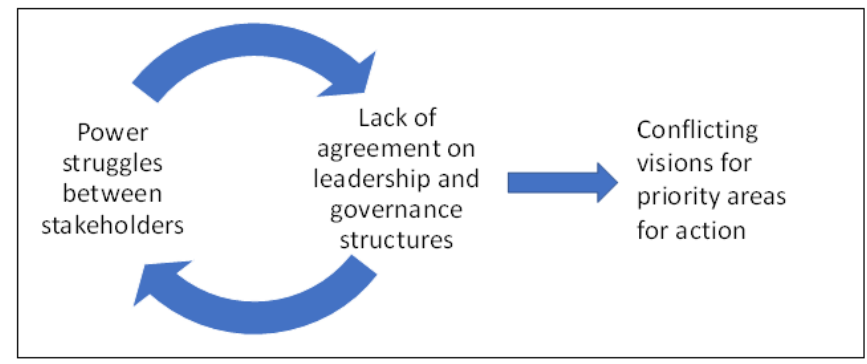

Figure 1 Vicious cycle impeding a shift from expressed political commitment to long-term systemic changes for operationalising One Health.

than remaining confined to select organisations and a distinct global policy community. ${ }^{34}$

The institutions with the greatest hand in guiding and governing the One Health movement (FAO, OIE, WHO) were described by many interviewees to have adopted an undefined and unrealistic vision of One Health that has allowed for subgroups and stakeholders to shift operationalisation in directions most aligned to maintaining their own interests and influence in the movement, as illustrated in figure $1 .{ }^{18}$ This 'functional adoption' of One Health enables dominant subgroups or sectors within the movement to shape narrative, knowledge, policy responses and allocation of financial resources to issues they are mandated to address or that that they perceive as important by increasing ambiguity and diluting the meaning and evidence for the approach. ${ }^{10182531}$ Strong governance and leadership is of particular importance for building a shared vision and for defining agreed and actionable strategic priorities; in lieu of this, subgroups within a movement may compete over which issues should take priority. Growing momentum around Planetary Health, for example, may reflect the differences in vision for specific areas of work to be prioritised between One Health stakeholders and others who also want to increase collaboration between human, animal and environmental health stakeholders. ${ }^{38} 39$

Our results also resonate with findings described elsewhere in the literature on the challenges facing global health movements. ${ }^{34} 4041$ Indeed, the global health field has witnessed the rise, short-term persistence and decline of several movements ${ }^{34342}$ recognition of which has led researchers to investigate the determinants of political priority for global health movements. ${ }^{34} 3541-45$ Through this research, the governance of global health movements-establishing informal and formal institutions to facilitate collective action ${ }^{40}$ - appears to emerge as a particularly important determinant of sustained attention to global health issues, where cohesive governance arrangements have contributed to the success of networks addressing some issues (such as tobacco control $^{46}$ and maternal mortality ${ }^{44}$ ), whereas fragmented governance has impeded progress for others (such as alcohol harm ${ }^{47}$ and early childhood development ${ }^{48}$ ). The Scaling Up Nutrition initiative is an example where challenges existed in converting global commitments-such 
as the UN Decade of Action on Nutrition-into coherent action on the ground, where narrow coalition-building across different sectors, internal conflict between stakeholders, a lacking or inconsistent evidence base and fragmented governance arrangements have been outlined as key barriers to achieving results. ${ }^{41}{ }^{49}$ This is also illustrated by the primary healthcare movement, where momentum slowed as the vision offered by leaders was deemed unrealistic and ultimately subgroups splintered determined by their own interests, priorities and desire to demonstrate measurable impact. ${ }^{50}$

In addition to highlighting some new challenges, we also identified a policy window-the current high-level commitments to combat the 'global crisis' of AMR ${ }^{51-53}$ as a potentially important opportunity to advance changes to structures and institutions such that collaborative working according to One Health principles is better supported. AMR was perceived to generate the required sense of urgency for action in the way that the West African Ebola epidemic and other outbreaks have in recent years. Owing to the wider geographic and longer-term impact of AMR (as compared with other emerging infectious diseases that affect a smaller group of countries), it was identified as a uniquely powerful platform to enable sustained commitment and action on One Health going forward. Indeed, many of the high-level political statements in support of the One Health approach have been released in the context of addressing AMR ${ }^{53-56}$ Nevertheless, it remains to be seen how well global attention to AMR is capitalised to further operationalise One Health; we found that the majority of OHNs do not appear to focus on AMR yet despite action on communicable diseases dominating their activities, perhaps because other health issues are considered more pressing in the local contexts where these networks work. Interviewees felt that using the window of opportunity afforded by AMR to operationalise One Health may produce political support and generate measurable progress on tangible outcomes as, for example, was seen with other issue-specific initiatives, such as the Global Fund to Fight AIDS, Tuberculosis and Malaria. ${ }^{42} 57$ However, using this policy window also runs the risk of skewing countries' activities towards a health issue that may not be a domestic priority and precipitating more disease-specific or 'vertical' programmes, especially since current One Health operationalisation remains largely focused on specific health issues, such as pandemic influenza preparedness. ${ }^{1}$ We see this tension occurring with another initiative that has become a buzzword among global health actors-'Health Systems Strengthening' (HSS). A number of programmes claim to be HSS while focusing on disease-specific interventions, which risks undermining the movement's goal of inclusive and effective health systems. ${ }^{58}$

We summarise specific recommendations for sustaining political commitment to One Health, based on views of our interviewees, in box 2. These include increasing civil society engagement in One Health and building links
Box 2 Specific recommendations to further One Health operationalisation emerging from this study

1. Capitalise on the 'policy window' afforded by recent global attention to AMR in order to galvanise support for the broader implementation of the One Health approach over the long-term and across various contexts

2. Encourage civil society mobilisation and inclusion in decision-making around One Health to build stronger links between policymakers, funders and communities implementing and affected by One Health programmes on the ground.

3. Expand current joint education programmes for human, animal and environmental health specialists at earlier career stages, including training in technical, leadership and partnership skills.

4. Improve monitoring and evaluation of the numerous One Health initiatives to strengthen the evidence base on the effectiveness of One Health approaches, the economic benefits of their application and best practices in the field. Promote wider uptake of tools to standardise monitoring and reporting.

5. Investigate the most appropriate approaches for guiding the implementation of One Health at the global, regional, national and subnational level. In the meantime, immediate action can be taken to facilitate coordination of One Health activities, for example, by maintaining a global database.

between grassroots organisations, policymakers and funders. With the current political attention to AMR, rapid engagement of civil society groups to draw attention to locally relevant health issues may help sustain momentum to encourage longer-term investments in operationalising One Health. Interviewees also proposed more joint training schemes for human, animal, and environmental health specialists at earlier career stages in order to build an understanding of and respect for the other disciplines. ${ }^{5960} \mathrm{~A}$ further critical recommendation for translating the stated political support for One Health into sustained action with measurable impact is to draw on the work of other disciplines, for example, in the social sciences, to develop standardised indicators and monitoring systems to strengthen the One Health evidence base. This will help to assess the comparative effectiveness of applying a One Health approach, the economic benefits of its application and to identify best practices in the field. ${ }^{2} 122960-63$

While our analysis indicated potential solutions to several of the challenges identified for implementing One Health approaches, we did not identify straightforward strategies to tackle serious impediments related to power struggles between human, animal and environmental health sectors and the lack of an agreed leadership or governance structure. While clear and strong governance structures have been found to be important for sustaining political commitment for diverse global health movements, ${ }^{45} 48$ wider agreement about overarching governance arrangements (currently lacking for One Health) is an essential first step. In the case of One Health, we found polarised views about the need for a 
centralised structure for strategic coordination and leadership.

Our study is not without limitations that should be considered when interpreting our results. We attempted to collect information about the sector (human, animal or environment) that study participants most closely identified with, in order to understand potential biases in their perspectives, but found that several felt most comfortable labelling themselves as 'One Health'. We were therefore unable to consider whether the primary training or sector of interviewees was relevant in shaping their views. As we focused our qualitative study on key informants based in influential funding and policymaking organisations operating at the global level (who we found to be based in Europe and the USA), we acknowledge that the analysis does not represent views from low-income and middle-income countries. In particular, future studies could focus on East Asia as this region was mentioned as being ahead in operationalising the One Health approach. However, we successfully engaged all senior policymakers and funders that we aimed to interview in line with our study scope and reached a high degree of consistency with our findings. We also validated our findings by sharing some preliminary results with a subset of informants and receiving feedback.

\section{CONCLUSION}

Since 2010, political and financial attention to One Health has surged, and One Health has been framed by the Tripartite to have a broader scope. These developments have been accompanied by an increase in the number of organisations conducting diverse activities under the One Health umbrella and by heightened power struggles around which stakeholders have the authority to define One Health. Owing to a perceived lack of guidance on priority focus areas and on how best to operationalise One Health, concerns were expressed that stakeholders are pulling operationalisation in directions most aligned to their own interests, thereby splintering the movement and stifling progress on systemic change. While the international attention to AMR is highlighting the need for investment in a One Heath approach, there is a risk that One Health initiatives will remain focused on disease-specific issues and that structural changes to sustain collaboration between sectors will be neglected. Several opportunities were identified to capitalise on the current growth in One Health initiatives and funding. Better monitoring and evaluation of the numerous ongoing activities is needed to strengthen the evidence base to support future funding and allow development of more precise guidelines on best practices. Further, to bridge divides between stakeholders, capacity building activities should additionally focus on collaboration skills and joint training of human, animal and environmental health specialists.

Contributors MK conceived the study and all authors developed the methods. EM, JS and MK collected and analysed the data. JS, EM and MK wrote the first draft of the manuscript. All authors contributed to sections of the manuscript and revised and approved the final manuscript.

Funding The authors have not declared a specific grant for this research from any funding agency in the public, commercial or not-for-profit sectors.

Competing interests None declared.

Patient consent Not required.

Ethics approval Ethical approval for the research was received from the London School of Hygiene \& Tropical Medicine ethics committee.

Provenance and peer review Not commissioned; externally peer reviewed. Data sharing statement № additional data are available.

Open access This is an open access article distributed in accordance with the Creative Commons Attribution Non Commercial (CC BY-NC 4.0) license, which permits others to distribute, remix, adapt, build upon this work non-commercially, and license their derivative works on different terms, provided the original work is properly cited, appropriate credit is given, any changes made indicated, and the use is non-commercial. See: http://creativecommons.org/licenses/by-nc/4.0/.

\section{REFERENCES}

1. Lee K, Brumme ZL. Operationalizing the one health approach: the global governance challenges. Health Policy Plan 2013;28:778-85.

2. Baum SE, Machalaba C, Daszak P, et al. Evaluating one health: are we demonstrating effectiveness? One Health 2017;3:5-10.

3. Gibbs EP. The evolution of one health: a decade of progress and challenges for the future. Vet Rec 2014;174:85-91.

4. Atlas R, Rubin C, Maloy S. One Health-Attaining optimal health for people, animals, and the environment adopting the one health paradigm is crucial for understanding emerging diseases and meeting future challenges in global health. Microbe Mag, 2010.

5. Gebreyes WA, Dupouy-Camet J, Newport MJ, et al. The global one health paradigm: challenges and opportunities for tackling infectious diseases at the human, animal, and environment interface in lowresource settings. PLoS Negl Trop Dis 2014;8:e3257.

6. Lelieveld J, Evans JS, Fnais M, et al. The contribution of outdoor air pollution sources to premature mortality on a global scale. Nature 2015;525:367-71.

7. Climate \& Clean Air Coalition to Reduce Short-Lived Climate Polutants. Addressing black carbon and methane emissions from the agriculture sector. Available: http://www.ccacoalition.org/en/ initiatives/agriculture [Accessed 22 May 2018].

8. Murray M, Holmes P, Wright N, et al. History of one health and one medicine. Vet Rec 2014:174-227. LP-227.

9. Lerner H, Berg C. A comparison of three holistic approaches to health: one health, EcoHealth, and planetary health. Front Vet Sci 2017;4.

10. Galaz V, Leach M, Scoones I. Global narratives: the political economy of One Health. In: Bardosh K, ed. One Health: Science, Politics and Zoonotic Disease in Africa. New York: Routledge, 2016: 21-37.

11. American Veterinary Medical Association, 2008. One Health-a new professional imperative. Available: https://www.avma.org/KB/ Resources/Reports/Documents/onehealth_final.pdf

12. Davis MF, Rankin SC, Schurer JM, et al. Checklist for one health epidemiological reporting of evidence (COHERE). One Health 2017;4:14-21.

13. Cunningham AA, Scoones I, Wood JLN. One health for a changing world: new perspectives from Africa. Philos Trans $R$ Soc Lond B Biol Sci 2017;372:20160162.

14. Rabinowitz PM, Kock R, Kachani M, et al. Toward proof of concept of a one health approach to disease prediction and control. Emerg Infect Dis 2013;19.

15. Berthe FCJ, Bouley T, Karesh WB, et al. 123023. Operational framework for strengthening human, animal and environmental public health systems at their interface. Washington, D.C: The World Bank; 2018. http://documents.worldbank.org/curated/en/ 703711517234402168/Operational-framework-for-strengtheninghuman-animal-and-environmental-public-health-systems-at-theirinterface.

16. FAO, OIE, WHO, 2010. Sharing responsibilities and coordinating global activities to address health risks at the animal-humanecosystems interfaces, a tripartite concept note. Available: http:// www.who.int/influenza/resources/documents/tripartite_concept note_hanoi_042011_en.pdf?ua=1

17. World Health Organization, 2018. Memorandum of understanding between the United Nations food and agriculture organization and 
the world Organisation for animal health and the World Health organization. Available: http://www.who.int/zoonoses/MoUTripartite-May-2018.pdf?ua $=1$

18. Chien YJ. How did international agencies perceive the avian influenza problem? The adoption and manufacture of the 'One World, One Health' framework. Sociol Health IIIn 2013;35:213-26.

19. FAO, OIE, WHO, 2017. The Tripartite's Commitment Providing multisectoral, collaborative leadership in addressing health challenges. Available: http://www.who.int/zoonoses/tripartite_oct2017.pdf?ua=1

20. OIE, 2017. OIE, FAO and who enlarge their collaboration commitment to face health challenges. Available: http://www.oie. int/en/for-the-media/press-releases/detail/article/oie-fao-and-whoenlarge-their-collaboration-commitment-to-face-health-challenges/

21. Mazet JA, Uhart MM, Keyyu JD. Stakeholders in one health. Rev Sci Tech 2014:33:443-52.

22. Khan MS, Rothman-Ostrow P, Spencer J, et al. The growth and strategic functioning of one health networks: a systematic analysis. Lancet Planet Health 2018;2:e264-73.

23. USAID. Emerging pandemic threats program (EPT-2). Available: https://www.usaid.gov/what-we-do/global-health/pandemicinfluenza-and-other-emerging-threats/programs [Accessed 17 Oct 2018].

24. The Wellcome Trust. Priority Area: our planet, our health: responding to a changing world, 2015.

25. Okello AL, Bardosh K, Smith J, et al. One health: past successes and future challenges in three African contexts. PLoS Negl Trop Dis 2014;8:e2884.

26. Galaz V, Leach M, Scoones I, et al. The political economy of one health research and policy, steps Working paper 81. Brighton: STEPS Centre, 2015.

27. Roger F, Caron A, Morand S, et al. One health and EcoHealth: the same wine in different bottles? Infect Ecol Epidemiol 2016;6.

28. Zinsstag J. Convergence of EcoHealth and one health. Ecohealth 2012;9:371-3

29. Rushton J, Häsler B, De Haan N, et al. Economic benefits or drivers of a 'One Health' approach: Why should anyone invest? Onderstepoort J Vet Res 2012;79:75-9.

30. Leboeuf A. Heath and Environment Reports, No.7. Making sense of one health: cooperating at the Human-Animal-Ecosystem health interface: Institut français des relations internationales; 2011.

31. Bardosh KL, Scoones JC, Grace D, et al. Engaging research with policy and action: what are the challenges of responding to zoonotic disease in Africa? Philos Trans R Soc Lond B Biol Sci 2017;372:20160172.

32. Valeix SF. One health integration: a proposed framework for a study on veterinarians and zoonotic disease management in Ghana. Front Vet Sci 2018;5.

33. Fernald DH, Duclos CW. Enhance your team-based qualitative research. Ann Fam Med 2005;3:360-4.

34. Shiffman J, Smith S. Generation of political priority for global health initiatives: a framework and case study of maternal mortality. Lancet 2007;370:1370-9.

35. Shiffman J, Quissell K, Schmitz HP, et al. A framework on the emergence and effectiveness of global health networks. Health Policy Plan 2016:31(Suppl 1):i3-16.

36. UNAIDS. How AIDS changed everything - MDG6: 15 years, 15 lessons of hope from the AIDS response. Geneva, 2015.

37. World Health organization. The essential role of civil society: the 2006 report on the global AIDS epidemic. Geneva, 2006.

38. UN Environment, 2018. Un environment and world Health organization agree to major collaboration on environmental health risks. Available: https://www.unenvironment.org/news-and-stories/ press-release/un-environment-and-world-health-organization-agreemajor

39. Whitmee S, Haines A, Beyrer C, et al. Safeguarding human health in the Anthropocene epoch: report of the Rockefeller Foundation-Lancet Commission on planetary health. Lancet 2015;386:1973-2028.

40. Shiffman J. Four challenges that global health networks face. Int $J$ Health Policy Manag 2017:6-189.

41. Baker $\mathrm{P}$, Hawkes $\mathrm{C}$, Wingrove $\mathrm{K}$, et al. What drives political commitment for nutrition? A review and framework synthesis to inform the United Nations decade of action on nutrition. BMJ Glob Health 2018;3:e000485.
42. Shiffman J. A social explanation for the rise and fall of global health issues. Bull World Health Organ 2009;87:608-13.

43. Shiffman J. Networks and global health governance: introductory editorial for health policy and planning supplement on the emergence and effectiveness of global health networks. Health Policy Plan 2016;31(Suppl 1):i1-2.

44. Smith SL, Rodriguez MA. Agenda setting for maternal survival: the power of global health networks and norms. Health Policy Plan 2016;31(Suppl 1):i48-59.

45. Quissell K, Walt G. The challenge of sustaining effectiveness over time: the case of the global network to stop tuberculosis. Health Policy Plan 2016;31(Suppl 1):i17-32.

46. Gneiting U. From global agenda-setting to domestic implementation: successes and challenges of the global health network on tobacco control. Health Policy Plan 2016;31(Suppl 1):i74-86.

47. Schmitz HP. The global health network on alcohol control: successes and limits of evidence-based advocacy. Health Policy Plan 2016;31(Suppl 1):i87-97.

48. Shawar YR, Shiffman J. Generation of global political priority for early childhood development: the challenges of framing and governance. Lancet 2017;389:119-24.

49. Gillespie S, Menon P, Kennedy AL. Scaling up impact on nutrition: what will it take? Adv Nutr 2015;6:440-51.

50. Cueto $M$. The origins of primary health care and selective primary health care. Am J Public Health 2004;94:1864-74.

51. WHO. Global action plan on Antimicrobial resistance, 2015.

52. Group of 20. Berlin Declaration of the G20 health ministers. Berlin, 2017.

53. United Nations (UN), 2016. High-level meeting on Antimicrobial resistance. Available: http://www.un.org/pga/71/event-latest/highlevel-meeting-on-antimicrobial-resistance/

54. Chan M. Who Director-General addresses G7 health ministers meeting on Antimicrobial resistance. Berlin: World Health Organization, 2015.

55. Elliott A, Nerima B, Bagaya B, et al. The G7 and global health: inaction or incisive leadership? 2015.

56. Commonwealth Secretariat, 2016. Health security and universal coverage on the agenda of Commonwealth Health ministers. Available: http://thecommonwealth.org/media/press-release/healthsecurity-and-universal-coverage-agenda-commonwealth-healthministers

57. Reich MR, Takemi K, Roberts MJ, et al. Global action on health systems: a proposal for the Toyako G8 Summit. Lancet 2008;371:865-9.

58. Marchal B, Cavalli A, Kegels G. Global health actors claim to support health system strengthening: is this reality or rhetoric? PLoS Med 2009;6:e1000059.

59. Rabinowitz PM, Natterson-Horowitz BJ, Kahn LH, et al. Incorporating one health into medical education. BMC Med Educ 2017;17.

60. Zinsstag J, Mackenzie JS, Jeggo M, et al. Mainstreaming one health. Ecohealth 2012;9:107-10.

61. Grace D. The business case for one health. Onderstepoort J Vet Res 2014;81:1-6.

62. Queenan Ket al. Roadmap to a one health agenda 2030. $C A B$ Reviews 2017;12:1-17.

63. Häsler B, Cornelsen L, Bennani $\mathrm{H}$, et al. A review of the metrics for one health benefits. Rev Sci Tech 2014;33:453-64.

64. Connecting Organisations for Regional Disease Surveillance (CORDS). Available: https://www.cordsnetwork.org/ [Accessed 30 Jan 2019].

65. One Health Commission. About the Commission. Available: https:// www.onehealthcommission.org/en/why one health/about the commission/ [Accessed 17 Oct 2018].

66. USAID, 2014. Preparedness and Response (P\&R). Available: https:// www.usaid.gov/sites/default/files/documents/1864/preparednessresponse-factsheet $\% 20 \% 281 \% 29$. df

67. USAID, n.d. Preparedness \& Response: One Health in Action, Where we work. Available: http://preparednessandresponse.org/where-wework/ [Accessed 16 Oct 2018].

68. USAID, n.d. One Health Workforce: Developing a global workforce to prevent, detect, and respond to infectious disease threats. Available: https://www.usaid.gov/sites/default/files/documents/1864/OHW_ Overview_Handout_2016-ct-508-1.pdf 